\title{
Bilateral phaeochromocytoma during pregnancy
}

\author{
Chandrika N Wijeyaratne', A H Sheriffdeen ${ }^{2}$ and H R Seneviratne ${ }^{3}$
}

(Index words: Biochemical assessment, diagnosis, management).

\section{Introduction}

Phaeochromocytoma during pregnancy is rare and life-threatening to both mother and fetus (1). Pregnancy leads to diagnostic difficulty, whereas early diagnosis and appropriate management improves the prognosis (2). Only a few hundred cases managed during pregnancy have been reported and, as far as we know, there are no publications of bilateral tumour managed during pregnancy. We report a pregnancy complicated by bilateral phaeochromocytoma managed during a triage situation in Sri Lanka.

\section{Case report}

A 25-year old housewife was seen at 18 weeks of amenorrhoea at the University Obstetrics and Gynaecology Unit, De Soysa Hospital for Women in Colombo. She was in her second pregnancy. An intrauterine death had occurred at 35 weeks of her first pregnancy the previous year, when she had been found to be mildly hypertensive. She had delivered a macerated fetus weighing $1800 \mathrm{~g}$ at a district hospital. Her hypertension had not been followed up. She had experienced dizzy spells associated with profuse sweating, starting around 24 weeks of gestation of her first pregnancy, increasing in frequency in the latter stages. These symptoms had regressed after delivery.

At the antenatal booking for her second pregnancy she was asymptomatic. There was no family history of significant disease. She was admitted to hospital for evaluation as her resting blood pressure was $140 / 100 \mathrm{mmHg}$. Blood pressure recordings made in the seated and left lateral positions fluctuated between $160 / 110$ and $130 / 70 \mathrm{mmHg}$. She had no fibromata, naevi, pigmentation or pedal oedema. Her resting heart rate was $90 /$ minute, and all peripheral pulses were palpable and synchronous. She had no cardiomegaly or abnormal heart sounds. Abdominal palpation showed that the uterine fundal height corresponded to the period of amenorrheoa. The central nervous system was clinically normal with normal ocular fundi. Over the next two weeks she developed episodes of headache, flushing, dizziness and sweating 4 to 5 times a day. She confirmed that these symptoms were a recurrence of what she had experienced in her first pregnancy. She was treated with nifedipine $30 \mathrm{mg} /$ day and hydralazine $150 \mathrm{mg} /$ day orally.

Her biochemical and endocrine investigations (Tables 1 and 2) revealed an elevated urinary vanillyl mandelic acid excretion and diabetes mellitus. The renal profile, serum calcium, thyroid hormone and cortisol levels were normal. Ultrasound scanning of her abdomen showed a right suprarenal mass measuring $10 \times 18 \mathrm{~cm}$, and the left suprarenal gland was normal. Her renal dimensions and outlines were normal. There was an intrauterine single live fetus with the fetal size and liquor volume corresponding to her dates. A resting electrocardiogram and two-dimensional echocardiography were normal. An elective adrenalectomy was planned at 21 weeks of gestation. The blood pressure was controlled preoperatively with prazosin and phenoxybenzamine. She was started on human premixed (30: 70) insulin injection 20 units twice daily. Surgery had to be performed in a triage situation following a major bomb blast in Colombo the evening before. Consequently, all elective operations had been cancelled, and there was a serious shortage of intensive care facilities. In view of her extremely labile blood pressure and hyperglycaemia, the attending team decided to proceed with planned surgery, despite constraints. Her blood pressure was controlled peri-operatively with intravenous nitroglycerine. A $12 \times 18 \mathrm{~cm}$ right suprarenal tumour was removed. Exploration of the left adrenal gland was equivocal, made very difficult by the gravid uterus. Postoperatively her blood pressure was $160 / 100 \mathrm{~mm} \mathrm{Hg}$, and easily controlled with hydralazine $50 \mathrm{mg}$ three times a day. She remained normoglycaemic without insulin. Fetal ultrasound revealed satisfactory fetal well being. On the tenth postoperative day she experienced a recurrence of dizziness and palpitations. She was normolensive, had no postural hypotension and was not anaemic. Repeat estimation of 24 hour urinary VMA excretion showed an elevated excretion at $13 \mathrm{mg} /$ day. Detailed ultrasound of left adrenal gland retroperitoneal region showed no tumour. She was thereafter managed as an outpatient with fortnightly review.

Table 1. Results of antenatal biochemical assessment

$\begin{array}{ll}\text { Blood urea } & 3.0 \mathrm{mmol} / 1 \text { (normal) } \\ \text { Serum sodium } & 138 \mathrm{mmol} / / \\ \text { Serum potassium } & 3.9 \mathrm{mmol} / 1 \\ \text { Serum creatinine } & 80 \mu \mathrm{mol} / 1 \text { (normal) } \\ \text { Creatinine clearance } & 112 \mathrm{ml} / \mathrm{min} / \mathrm{m}^{2} \\ \text { Urine } & \text { proteins nil; deposits nil } \\ \text { Haemoglobin } & 12 \mathrm{~g} / \mathrm{dl} \\ \text { Packed cell volume } & 0.316 \\ 75 \text { g oral glucose tolerance test: } & \text { Fasting } 7 \mathrm{mmol} / 1 \\ & 1 \text { hour } 13 \mathrm{mmol} / 1 \\ & 2 \text { hour } 11 \mathrm{mmol} / \mathrm{l}\end{array}$

'Senior Lecturer and, '3Professor and Head, Department of Obstetrics and Gynaecology, ${ }^{2}$ Professor and Head, Department of Surgery, Faculty of Medicine, University of Colombo. (Revised version accepted 2 April 2000). 
Table 2. Results of antenatal endocrine laboratory assessment

24 hour urinary vanillyl mandellic acid (VMA)

Serum calcium

Standard calcium

Serum albumin

Sẹrum free thyroxine

9 ạ.m. serum cortisol
$13 \mathrm{mg} /$ day at 19 weeks' gestation (normal excretion $0.5 \mathrm{mg}$ )

$32 \mathrm{mg} /$ day at 20 weeks' gestation

$2.22 \mathrm{mmol} / \mathrm{h}$

$2.13 \mathrm{mmol} / \mathrm{(2.1302.43)}$

$44 \mathrm{~g} /$

$1.0 \mathrm{mlU} / \mathrm{ml}$ (normal)

$248 \mathrm{nmol} / 1$ (normal)
She remained normotensive on methyldopa $500 \mathrm{mg} /$ day. Her glycaemic control was maintained on diet alone until she required human insulin 8 units daily from 35 weeks. There was asymmetrical fetal growth retardation with a satisfactory liquor content.

An elective lower segment caesarean section was performed at 37 weeks under epidural analgesia. A baby girl weighing $2140 \mathrm{~g}$ with an Apgar score of 9 and 10 at 1 and 5 minutes respectively was delivered. The baby remained well and was breastfed. The mother was asymptomatic and her blood pressure was $140 / 100 \mathrm{mmHg}$ postpartum, and her urinary VMA had risen to $22 \mathrm{mg} /$ day. Computerised tomography confirmed the presence of a tumour in the left suprarenal. At 8 weeks postpartum, she underwent surgical excision of the left suprarenal tumour. Postoperatively she was asymptomatic, normotensive and normoglycaemic, and on steroid replacement alone. Her urinary VMA excretion remained within normal limits. One year after surgery, she remains well. She has an intra-uterine device for contraception.

\section{Discussion}

Phaeochromocytoma is a rare neuroectodermal tumour which can present with a broad range of clinical manifestations. A major manifestation is hypertension, which may resemble pregnancy-induced hypertension (PIH). Differentiation between these two conditions is not always easy, and a high index of clinical suspicion is the key to diagnosis. Phaeochromocytoma must be considered in any pregnant woman with severe hypertension, particularly if noted before $\mathbf{2 0}$ weeks of gestation, and is associated with sweating, palpitations or headache (2). The combination of hypertension and diabetes mellitus should also alert the clinician to the diagnosis (3). Abdominal palpation and fetal movements are recognised precipitants of symptoms of catecholamine excess in patients with phaeochromocytoma (4).

Estimation of catecholamine in urine and blood is a reliable method of confirming the diagnosis. Pregnancy does not alter urinary catecholamine levels (5). Radiological tests to localise the tumour may not be easily interpreted because of a gravid uterus (6). Ultrasound and magnetic reso- nance imaging can be used to localise tumour during the antepartum period.

Our suspicion of residual tumour following resection of the right suprarenal tumour was supported by the recurrence of symptoms, a rise in blood pressure and blood glucose level, and a rise in urinary VMA. The diagnosis was confirmed by postpartum computerised tomography. Maternal deaths have been reported in unsuspected cases of phaeochromocytoma, but those diagnosed antenatally and managed appropriately have had successful maternal and fetal outcomes (1). Surgery is the only curative method available, and the exact timing of surgery during pregnancy is a critical issue. Following confirmation of the diagnosis, alpha blockade is essential and beta blockade may also be necessary. Tumour resection has a good maternal and fetal outcome in the first and second trimesters. When detected in advanced pregnancy, medical management and elective caesarean section at term followed by tumour resection is recommended (7). Preoperative alpha-receptor blockade, good surgical technique, careful anaesthetic management and monitoring have reduced perioperative maternal and fetal mortality below $3 \%(8)$.

Bilateral tumours occur in approximately $10 \%$ of subjects with phaeochromocytoma. As far as we know bilateral phaeochromocytoma has not been reported in the world literature during pregnancy. Following bilateral adrenalectomy for bilateral phaeochromocytoma, with a recurrence at an extra-adrenal site during pregnancy a successful pregnancy outcome has been reported (9). Combining tumour resection of radiologically localised tumours with caesarean section has been reported to be successful by many workers $(10,11)$. Ultrasound scanning for remnant tumour being negative in our patient, and the advanced state of her pregnancy, with satisfactory fetal growth in the third trimester, justified our conservative approach to her management. This approach has the theoretical risk of malignant transformation, which is reported to be extremely rare (5). 


\section{References}

1. Lau P, Permezel M, Dawson P, Chester S, Collier N, Forbes I. Phacochromocytoma in pregnancy. Australian New Zealand Journal of Obstetrics and Gynaecology 1996; 34: 472-6.

2. Takai $Y$, Seki H, Kinoshita K. Phaeochromocytoma in pregnancy manifesting as hypertensive crisis induced by metoclorpramide. International Journal of Gynaecology and Obstetrics 1997; 59: 133-7.

3. Francis IR, Korobkin M. Phaeochromocytoma. Radiology Clinics of North America 1996; 34: 1101-12.

4. Monkelbaan JF, Cats HA, Beerenhout CH, Dullaaart RP, vanHaeften TW. Phaeochromocytoma in various disguises. Netherlands Journal of Medicine 1995; 47: 70-5.

5. Freier DT, Thompson NW. Phaeochromocytoma and pregnancy: the epitome of high risk. Surgery 1993; 114: 1148-52.

6. Botchan A, Hauser R, Kupfermine M, Grisaru D, Peyser MR, Lessing JB, Phaeochromocytoma in pregnancy: case report and review of literature. Obstetrics and Gynaecological Survey 1995; 50: 321-7.

7. Oishi S, Sato T. Phaeochromocytoma in pregnancy: a review of the Japanese literature. Journal of Endocrinology 1994; 41 : 219-25.

8. Hamilton A, Sirrs S, Schmidt N, Onrot J. Anaesthesia for phaeochromocytoma in pregnancy. Canadian Journal of Anaesthesia 1997; 44: 654-7.

9. Sweeney WJ, Katz VL. Recurrent phaeochromocytoma during pregnancy. Obstetrics and Gynaecology 1994; 83: 820-2.

10. Joffe D, Robbins R, Benjamin A. Caesarean section and phaeochoromocytoma resection in a patient with Von Hippel Lindau disease. Canadian Journal of Anaesthesia 1993; 40: 870-4.

11. Bakri YN, Ingemansson SE, Ali A Parikh S. Phaeochromocytoma and pregnancy: report of three cases. Acta Obstetrics and Gynaecology Scandinavia 1992; 71: 301-10. 